Published in final edited form as:

J Atten Disord. 2019 October ; 23(12): 1438-1453. doi:10.1177/1087054716629217.

\title{
Persistence and Subtype Stability of ADHD Among Substance Use Disorder Treatment Seekers
}

\author{
Sharlene Kaye ${ }^{1}$, Josep Antoni Ramos-Quiroga ${ }^{2}$, Geurt van de Glind ${ }^{3,4}$, Frances R. Levin ${ }^{5}$, \\ Stephen V. Faraone ${ }^{6}$, Steve Allsop ${ }^{7}$, Louisa Degenhardt ${ }^{1,8}$, Franz Moggi ${ }^{9,10}$, Csaba Barta ${ }^{11}$, \\ Maija Konstenius $^{12}$, Johan Franck ${ }^{12}$, Arvid Skutle ${ }^{13}$, Eli-Torild Bu $^{13}$, Maarten W. J. Koeter ${ }^{4}$, \\ Zsolt Demetrovics ${ }^{14}$, Máté Kapitány-Fövény ${ }^{14,15}$, Robert A. Schoevers ${ }^{16}$, Katelijne van \\ Emmerik-van Oortmerssen ${ }^{4,17}$, Pieter-Jan Carpentier ${ }^{18}$, Geert Dom ${ }^{19,20}$, Sofie \\ Verspreet $^{19,20}$, Cleo L. Crunelle ${ }^{4}$, Jesse T. Young ${ }^{7,8,21}$, Susan Carruthers ${ }^{7}$, Joanne Cassar ${ }^{1}$, \\ Melina Fatséas ${ }^{22}$, Marc Auriacombe ${ }^{22}$, Brian Johnson ${ }^{6}$, Matthew Dunn ${ }^{23}$, Ortal Slobodin ${ }^{24}$, \\ Wim van den Brink ${ }^{4}$
}

${ }^{1}$ University of New South Wales, Sydney, Australia ${ }^{2}$ Universitat Autònoma de Barcelona, Spain ${ }^{3}$ ICASA Foundation, Amsterdam, The Netherlands ${ }^{4}$ University of Amsterdam, Amsterdam, The Netherlands ${ }^{5}$ Columbia University, New York, NY, USA 6 Upstate Medical University, Syracuse, NY, USA ${ }^{7}$ Curtin University, Perth, Australia ${ }^{8}$ University of Melbourne, Australia ${ }^{9}$ University of Bern, Switzerland ${ }^{10}$ University of Fribourg, Switzerland ${ }^{11}$ Semmelweis University, Budapest, Hungary ${ }^{12}$ Karolinska Institutet, Stockholm, Sweden ${ }^{13}$ Bergen Clinics Foundation, Norway ${ }^{14}$ Eötvös Loránd University, Budapest, Hungary ${ }^{15}$ Nyírő Gyula Hospital Drug Outpatient and Prevention Center, Budapest, Hungary ${ }^{16}$ University of Groningen, The Netherlands ${ }^{17}$ Arkin Mental Health and Addiction Treatment Center, Amsterdam, The Netherlands ${ }^{18}$ Reinier van Arkel groep,'s-

Corresponding Author: Sharlene Kaye, National Drug and Alcohol Research Centre, University of New South Wales, Sydney, New South Wales 2052, Australia. s.kaye@unsw.edu.au.

Declaration of Conflicting Interests

The author(s) declared the following potential conflicts of interest with respect to the research, authorship, and/or publication of this article: G. van de Glind was, on one occasion, a consultant for Shire, for which he refused payment. In 2013, he received an unrestricted travel grant from Neurotech and he is a member (unpaid) of the advisory board of Neurotech. P. J. Carpentier received a fee for speaking at a conference organized by Eli Lilly in 2011. F. R. Levin reports Study Medication provided by US WorldMeds and being a consultant to GW Pharmaceuticals. She served as a consultant to Shire and Eli Lilly from 2005 to 2007. The ICASA

Foundation has reimbursed her for airfare to attend the Annual Meeting as a speaker. S. Kaye reports receiving unrestricted travel grants for participation in the World ADHD Federation conference in Berlin (2011) from Shire, Janssen, and Eli Lilly. In the past year, S. V. Faraone received consulting income and/or research support from Shire, Akili Interactive Labs, VAYA Pharma, SynapDx, and Alcobra and research support from the National Institutes of Health (NIH). His institution is seeking a patent for the use of sodiumhydrogen exchange inhibitors in the treatment of ADHD. In previous years, he received consulting fees or was on advisory boards or participated in continuing medical education programs sponsored by Shire, Alcobra, Otsuka, McNeil, Janssen, Novartis, Pfizer, and Eli Lilly. He receives royalties from books published by Guilford Press: Straight Talk About Your Child's Mental Health and Oxford University Press: Schizophrenia: The Facts. In the last 3 years, J. A. Ramos-Quiroga has been on the speakers' bureau and/or acted as consultant for Eli Lilly, Janssen-Cilag, Novartis, Shire, and Rubió. He also received travel awards (air tickets + hotel) for taking part in psychiatric meetings from Janssen-Cilag, Shire, and Eli Lilly. The ADHD Program chaired by him has received unrestricted educational and research support from Eli Lilly, Janssen-Cilag, Shire, and Rubió in the past 3 years. Z. Demetrovics received reimbursement for participating at symposia organized by Lundbeck (2011). G. Dom acted as a paid consultant for Lundbeck and received a speaker's fee and reimbursement for symposium attendance from GSK, Janssen Ph., Astra-Zeneca, and Eli Lilly. F. Moggi received a speaker's fee from Novartis and from Eli Lilly. M. Auriacombe and his institution report unrestricted grants and advisory board activities from RBK Pharmaceutical, Mundipharma, and D\&A Pharma. J. Franck declares his research group received an unrestricted research grant from Janssen-Cilag in 2007. The grant was received and administered by his university (Karolinska Institutet). W. van den Brink has received a fee from Eli Lilly for organizing a symposium on the role of impulsivity in psychiatric disorders and a speaker's fee from Eli Lilly for a presentation on the relationship between ADHD and addiction. Apart from the funding resources described above, the authors declare no other conflicts of interest. 
Hertogenbosch, The Netherlands ${ }^{19}$ University of Antwerp, Belgium ${ }^{20}$ Psychiatric Center Alexian Brothers, Boechout, Belgium ${ }^{21}$ The University of Western Australia, Perth, Australia ${ }^{22}$ Université de Bordeaux, France ${ }^{23}$ Deakin University, Geelong, Australia ${ }^{24}$ University of Haifa, Israel

\section{Abstract}

Objective-To examine ADHD symptom persistence and subtype stability among substance use disorder (SUD) treatment seekers.

Method-In all, 1,276 adult SUD treatment seekers were assessed for childhood and adult ADHD using Conners' Adult ADHD Diagnostic Interview for Diagnostic and Statistical Manual of Mental Disorders (4th ed.; DSM-IV; CAADID). A total of 290 (22.7\%) participants met CAADID criteria for childhood ADHD and comprise the current study sample.

Results-Childhood ADHD persisted into adulthood in $72.8 \%(n=211)$ of cases. ADHD persistence was significantly associated with a family history of ADHD, and the presence of conduct disorder and antisocial personality disorder. The combined subtype was the most stable into adulthood (78.6\%) and this stability was significantly associated with conduct disorder and past treatment of ADHD.

Conclusion-ADHD is highly prevalent and persistent among SUD treatment seekers and is associated with the more severe phenotype that is also less likely to remit. Routine screening and follow-up assessment for ADHD is indicated to enhance treatment management and outcomes.

\section{Keywords}

ADHD; subtypes; persistence; substance related disorders

\section{Introduction}

ADHD is characterized by inattention, hyperactivity, and/or impulsivity. Symptoms have historically been labeled as predominantly inattentive, predominantly hyperactive-impulsive, or combined "subtypes" of ADHD, although the Diagnostic and Statistical Manual of Mental Disorders (5th ed.; DSM-5; American Psychiatric Association [APA], 2013) replaced the term "subtypes" with "presentations" to reflect the observation that symptoms can manifest differently over time. As individuals with ADHD become older, symptoms can decrease in severity, with inattentive symptoms generally being more persistent than hyperactive-impulsive symptoms (Turgay et al., 2012; Wilens et al., 2009).

Although ADHD is often described as a childhood disorder, and can remit over time, ADHD symptoms persist into adulthood in about two thirds of cases, with associated impairment across multiple domains (Biederman, Petty, Evans, Small, \& Faraone, 2010; Faraone, Biederman, \& Mick, 2006; Turgay et al., 2012). Previous research has identified several risk factors for the persistence of childhood ADHD into adulthood: a family history of ADHD (Biederman et al., 1996; Biederman et al., 2010; Biederman, Petty, O’Connor, Hyder, \& Faraone, 2012), ADHD symptom severity and associated impairment (Biederman, Petty, Clarke, Lomedico, \& Faraone, 2011; Kessler et al., 2005; Lara et al., 2009), and comorbidity 
with conduct, oppositional defiant, mood, and anxiety disorders (Biederman et al., 1996; Biederman et al., 2011; Biederman et al., 2010; Biederman et al., 2012; Lara et al., 2009). Early psychosocial adversity, exposure to family conflict and parental psychopathology in particular, has also been shown to predict ADHD persistence (Biederman et al., 1996; Biederman et al., 2011; Biederman et al., 2012; Lara et al., 2009). Although the diagnosis of adult ADHD is based on clinical presentation and history, there is evidence to suggest that persistent ADHD can also be differentiated from remitted ADHD at the neurobiological level, including the presence of structural and functional brain differences between those with persistent and remitted ADHD (Mattfeld et al., 2014; Shaw et al., 2015).

Childhood ADHD is a well-documented, independent risk factor for the development of substance use disorders (SUDs) in adolescence and adulthood (Charach, Yeung, Climans, \& Lillie, 2011; Lee, Humphreys, Flory, Liu, \& Glass, 2011; Wilens et al., 2011) and is consistently overrepresented among SUD populations (van Emmerik-van Oortmerssen et al., 2012). Moreover, ADHD is associated with an earlier onset, greater severity, and increased chronicity of problematic substance use (Arias et al., 2008; Sullivan \& Rudnik-Levin, 2001; Wilens et al., 2011).

The persistence of ADHD symptoms beyond childhood further increases the likelihood of comorbid SUDs, with SUDs far more common among people with adult ADHD than among those with remitted childhood ADHD (Biederman et al., 2010; Molina \& Pelham, 2003; Sullivan \& Rudnik-Levin, 2001; Wilens et al., 2011). Increased risk of SUDs has also been reported in adults with subthreshold symptoms of ADHD (Faraone et al., 2007).

The risk of those with ADHD developing subsequent SUDs is not only increased among those with persistent ADHD symptoms, but also among those with particular symptom types, that is, with the hyperactive-impulsive (Chang, Lichtenstein, \& Larsson, 2012; Elkins, McGue, \& Iacono, 2007) or combined (Nogueira et al., 2014; Obermeit et al., 2013; Sprafkin, Gadow, Weiss, Schneider, \& Nolan, 2007; Tamm, Adinoff, Nakonezny, Winhusen, \& Riggs, 2012; Wilens et al., 2009) subtypes of ADHD. To date, however, factors associated with the persistence and presentation of ADHD symptoms among people with SUDs have received scant attention. Moreover, whether SUD trajectories differ between those whose ADHD symptoms remit versus persist, and between those with different ADHD subtypes, remains unclear. The current study examines (a) the persistence of ADHD symptoms into adulthood among people seeking treatment for SUDs, (b) correlates and childhood predictors of persistent ADHD, and (c) the stability of ADHD subtypes between childhood and adulthood.

\section{Method}

Data for this study were collected as part of the International ADHD in Substance Use Disorders Prevalence (IASP) study (van de Glind et al., 2013), a multi-site, cross-sectional study of ADHD among SUD treatment seekers conducted by the International Collaboration on ADHD and Substance Abuse (ICASA). The IASP study had approval from relevant ethics committees in each site and comprised two phases-a screening phase and a full 
assessment phase. For further details of the methodology of the IASP study, see van de Glind et al. (2013).

\section{Participants}

All individuals referred to recruiting drug and alcohol treatment centers during the study period (July 2008-November 2011) were invited to participate. Exclusion criteria were the inability to complete the screening questionnaire (e.g., due to limited literacy and/or cognitive impairment), severe physical or psychiatric problems, the inability to participate due to substance intoxication, and unwillingness to sign informed consent.

A total of 3,558 adults (aged 18-65 years) attending 47 drug and alcohol treatment centers in 10 countries (Australia, Belgium, France, Hungary, Norway, Spain, Sweden, Switzerland, Netherlands, and the United States) were screened for the presence of ADHD (screening phase). Screening interviews were conducted upon treatment intake. With the exception of those screened in Australia, Belgium, and the United States $(n=963)$, all screened participants were invited to participate in a further comprehensive psychiatric interview that took place 1 to 2 weeks after screening (full assessment phase), allowing for a period of patient stabilization in treatment.

Of the 3,558 participants screened, 1,276 completed the full assessment, during which they were evaluated for the presence of SUDs, childhood and current (adult) ADHD, and other comorbid psychiatric disorders. Detailed information on sample characteristics and ADHD prevalence can be found in van de Glind et al. (2014; van de Glind et al., 2013). A previous investigation indicated that there were no significant differences in terms of sociodemographic and clinical characteristics between the 1,276 participants completing the full assessment and the 1,319 participants who dropped out of the study after the screening phase (van de Glind et al., 2013).

Of those participants completing the full assessment, 290 (22.7\%) met criteria for a DSM-5 diagnosis of childhood ADHD and thus comprise the current study sample.

\section{Measures}

During the screening phase, a brief structured interview assessing demographics, past and current drug use, and details of current treatment episode was administered. Drug use history was ascertained by asking about the age of first use, years of regular use, and recent (30 days preceding treatment entry) use of alcohol, tobacco, heroin, methadone, opioids other than heroin or methadone, amphetamines, cocaine, ecstasy, benzodiazepines, and cannabis. Participants were also asked to specify their primary drug of current concern.

Diagnoses of ADHD were ascertained using Conners' Adult ADHD Diagnostic Interview for Diagnostic and Statistical Manual of Mental Disorders (4th ed.; DSM-IV; APA, 1994; CAADID; Epstein, Johnson, \& Conners, 2001). Part I of the CAADID was selfadministered and obtains information on obstetric complications (e.g., maternal substance use during pregnancy, premature birth, low birth weight), temperamental characteristics (e.g., impulsivity, hyperactivity), developmental milestones, environmental circumstances (e.g., trauma, neglect, family violence), medical history, and familial psychiatric problems to 
assess early risk factors for ADHD. Past and current social, academic, and occupational functioning is also assessed.

Given the high rates of childhood trauma among SUD populations (Conroy, Degenhardt, Mattick, \& Nelson, 2009; Farrugia et al., 2011), the current study employed the CAADID to examine childhood adversity (i.e., physical, emotional, and sexual abuse; parental neglect; family violence; and other childhood trauma) as a potential risk factor for the persistence of ADHD. Self-reported familial risk factors (i.e., family history of diagnosed ADHD) and in utero substance (i.e., nicotine, alcohol, illicit drug) exposure, as measured by the CAADID, were also investigated as predictors of ADHD persistence.

Part II of the CAADID, administered by trained health professionals, is a semi-structured interview, assessing the five Diagnostic and Statistical Manual of Mental Disorders (4th ed., text rev.; DSM-IV-TR; APA, 2000) criteria for childhood and adult ADHD: (a) number of symptoms, (b) age of onset, (c) symptom pervasiveness, (d) level of impairment, and (e) whether or not the symptoms can be better explained by another psychiatric disorder. To obtain DSM- 5 diagnoses of ADHD, the age of onset threshold was increased from $<7$ years to $<12$ years and the number of symptoms required for an adult diagnosis reduced from six out of nine symptoms of inattention and/or hyperactivity-impulsivity to five out of nine symptoms (APA, 2013). A diagnosis of adult ADHD was contingent on a retrospectively obtained diagnosis of childhood ADHD meeting all five criteria, including the presence of six or more symptoms in childhood. This procedure results in conservative estimates of adult ADHD prevalence, as it is stricter than the DSM criteria for adult ADHD, which only require that "several" symptoms must be present before the age of 12 .

An additional measure of adult ADHD was provided by the ADHD module of the Mini International Neuropsychiatric Interview (MINI-Plus; Sheehan et al., 1998). The MINI-Plus was also used to assess prior and current episodes of mood disorders (i.e., major depression, bipolar disorder) and antisocial personality disorder (ASPD). Conduct disorder (CD) was retrospectively assessed using the ASPD module of the MINI-Plus, which establishes evidence of CD symptoms with an onset before the age of 15 . The borderline personality disorder module of the Structured Clinical Interview for DSM-IV Axis II Personality Disorders (SCID II; Williams et al., 1992) was also used. For details of the nature and level of comorbidity in this sample, see van Emmerik-van Oortmerssen et al. (2014).

\section{Data Analysis}

Initially, univariable analyses were conducted to identify statistically significant associations between demographic, drug use, and clinical variables and ADHD persistence. For continuous variables, $t$ tests were employed. For dichotomous categorical variables, unadjusted odds ratios (OR) and 95\% confidence intervals (CI) were reported. All primary statistical tests were determined significant at an alpha level of $p<.05$. Where multiple comparisons were conducted, Holm-Bonferroni corrections were performed to control the familywise error rate at $p<.05$.

To identify factors independently associated with persistence of ADHD symptoms and stability of ADHD subtypes, multivariable logistic regression analyses were conducted. Due 
to the hierarchical structure of the data, where participants were nested within sites (i.e., treatment centers), potential clustering by site was taken into account. Intracluster (or intraclass) correlation coefficients (ICCs), which provide a measure of the proportion of outcome variance attributable to between-cluster variance, with values close to 0 indicating negligible within-site clustering, were calculated for outcome variables of interest. Although the ICCs for the primary outcomes of ADHD persistence and subtype stability were less than .1 ( $\rho=.05$ and $\rho=.06$, respectively), we took a conservative approach and used the SPSS Complex Samples module, which adjusts for clustering. All regression models were adjusted at the participant level for age, gender, ethnicity (Caucasian = yes/no), level of education (graduated high school = yes/no), CD symptoms (yes/no), and past treatment of ADHD with stimulant medication (yes/no). All analyses were conducted using IBM SPSS Statistics 22 (IBM Corp, 2013).

\section{Results}

\section{Persistence of ADHD}

Of the 290 participants meeting childhood criteria for ADHD, 211 also met criteria for adult ADHD, representing a persistence rate of $72.8 \%$, and thus comprised the "persistent ADHD" group. The remaining 79 who did not meet criteria for adult ADHD comprised the "remitted ADHD" group.

There was no significant association between the age of the participant and the likelihood of full syndrome ADHD persistence $(\mathrm{OR}=0.99,95 \% \mathrm{CI}=[0.97,1.02], p=.703)$. Likewise, age was not associated with the persistence of $\geq 5$ symptoms from either the inattentive (OR $=0.99,95 \% \mathrm{CI}[0.97,1.01], p=.374)$ or hyperactive-impulsive $(\mathrm{OR}=0.98,95 \% \mathrm{CI}=[0.96$, $1.01], p=.152$ ) domains.

\section{Correlates of ADHD Persistence}

Sociodemographic and treatment characteristics-As shown in Table 1, there were no significant sociodemographic differences or differences in the type of treatment setting (i.e., inpatient vs. outpatient) between the persistent ADHD and remitted ADHD groups.

Substance use history-In $60 \%$ of cases, illicit drugs, most commonly cannabis (17\%), amphetamines (15\%), and heroin (11\%), were nominated as the primary drug of concern upon entry to treatment. Of the $40 \%$ who nominated alcohol as their primary drug of concern, however, one third (33.6\%) had also used illicit drugs in the month preceding treatment.

Both the persistent and remitted ADHD groups reported initiating nicotine, alcohol, and illicit drug use from an average age of 14 onwards (Table 2), at least 2 years after the onset of ADHD symptoms in childhood. Those with persistent ADHD reported an earlier initiation of amphetamine use, a longer duration of regular cocaine use, and more days of cocaine use in the month prior to treatment entry than the remitted ADHD group. The persistent ADHD group were more likely to report illicit drugs (vs. alcohol) -amphetamine and cocaine in particular - as their primary substance of concern; however, these differences, 
together with those in substance use initiation, duration, and frequency, did not remain significant after Holm-Bonferroni correction (Table 2).

The majority of participants (83.1\%) were lifetime polydrug users, with almost half (48.3\%) engaging in polydrug use in the month prior to treatment. Following correction for multiple comparisons, there were no significant between group differences in the extent of either lifetime or recent (i.e., month preceding treatment entry) polydrug use (Table 2).

Past ADHD diagnosis and treatment-Less than a quarter (21.9\%) of those meeting criteria for childhood ADHD had received a diagnosis of ADHD before study entry and an even smaller proportion had been treated with stimulant medication (14.5\%). There were no significant differences between the persistent and remitted ADHD groups with respect to the prevalence of past diagnosis and treatment of ADHD (Table 1).

Psychiatric comorbidity-Those with persistent ADHD were significantly more likely to meet criteria for ASPD (56.7\% vs. $34.7 \%, \mathrm{OR}=2.46,95 \% \mathrm{CI}=[1.40,4.33], p=.002$ ) and this association remained significant after Holm-Bonferroni correction (corrected $p<$. 008) and after adjusting for potential sociodemographic confounders (i.e., age, gender, ethnicity, level of education $)$ and past stimulant medication treatment $\left(\mathrm{OR}_{\mathrm{adj}}=2.31,95 \% \mathrm{CI}\right.$ $=[1.48,3.59], p=.001)$. As ASPD is difficult to disentangle from the behaviors inherent to an illicit drug-using lifestyle (e.g., lying, stealing, financial irresponsibility; Darke, Kaye, \& Finlay-Jones, 1998; Kaye, Darke, \& Finlay-Jones, 1998), further regression analysis controlling for an illicit SUD was conducted, following which ASPD remained independently associated with ADHD persistence $\left(\mathrm{OR}_{\mathrm{adj}}=1.84,95 \% \mathrm{CI}=[1.09,3.10], p\right.$ $=.026$ ).

Although ASPD was associated with the overall persistence of ADHD, this relationship was different for adult ADHD subtypes. After adjusting for the aforementioned confounders, comorbid ASPD was more likely among those with the combined subtype $\left(\mathrm{OR}_{\mathrm{adj}}=2.37\right.$, $95 \% \mathrm{CI}=[1.54,3.63], p=.001)$ and less likely among those with the inattentive subtype $\left(\mathrm{OR}_{\mathrm{adj}}=0.33,95 \% \mathrm{CI}=[0.12,0.90], p=.033\right)$. There was no significant association between ASPD and the hyperactive-impulsive subtype $\left(\mathrm{OR}_{\mathrm{adj}}=1.36,95 \% \mathrm{CI}=[0.36,5.15]\right.$, $p=.633)$.

\section{Predictors of ADHD Symptom Persistence}

Childhood ADHD subtype-Although there were no significant differences in proportions with the inattentive subtype in childhood, the persistent ADHD group was more likely to meet criteria for the combined subtype and less likely to meet criteria for the hyperactive-impulsive subtype than the remitted ADHD group (Table 3). After HolmBonferroni correction, however, these differences were no longer significant.

Familial, environmental, and psychopathological risk factors-Approximately one third (30.8\%) of the sample had a relative who had been diagnosed with ADHD. A family history of ADHD more than doubled the odds of persistent ADHD (Table 3). 
Childhood adversity was highly prevalent among participants meeting criteria for childhood ADHD. Of those who completed the section on childhood risk factors for ADHD in Part I of the CAADID $(n=246), 83.3 \%$ reported having experienced some form of childhood trauma. Almost two thirds (65.0\%) reported experiencing some type of abuse (i.e., sexual, physical, or emotional) in childhood, with emotional abuse the most commonly reported form (53.7\%). Other types of childhood trauma, including loss of a loved one, physical trauma, and witnessing traumatic events, were reported by nearly three quarters of participants (71.6\%) and over one third had experienced violence within the family (40.7\%) and parental neglect (36.7\%). The persistent ADHD group was more likely to report trauma other than abuse, as well as parental neglect, although these differences were no longer statistically significant after Holm-Bonferroni correction (Table 3).

Comorbid CD symptoms were prevalent, regardless of ADHD persistence. The odds of CD symptoms among the persistent ADHD group, however, were double that among the remitted ADHD group (Table 3).

After adjustment for possible confounding, both family history of $\mathrm{ADHD}\left(\mathrm{OR}_{\mathrm{adj}}=2.28\right.$, $95 \% \mathrm{CI}=[1.12,4.63], p=.026)$ and the presence of $\mathrm{CD}$ symptoms $\left(\mathrm{OR}_{\mathrm{adj}}=2.59,95 \% \mathrm{CI}=\right.$ $[1.02,6.61], p=.047)$ remained significant independent predictors of ADHD persistence.

\section{Stability of ADHD Subtypes}

Of the 211 participants diagnosed with adult (i.e., persistent) ADHD, the most common childhood subtype was "combined" (55.4\%), followed by the "inattentive" (24.6\%) and "hyperactive-impulsive" (19.9\%) subtypes.

Overall, childhood subtypes were stable into adulthood in $66.8 \%(n=141)$ of the cases. The combined subtype was the most stable, with the majority of those with the combined subtype in childhood meeting criteria for the combined subtype in adulthood (78.6\%; Figure 1). The inattentive subtype was the least stable, with less than half (48.1\%) retaining this symptom presentation in adulthood and the remainder transitioning to the combined subtype.

Of those 70 cases where a transition between childhood and adult subtypes occurred, the most common pathway of transition was from the inattentive subtype in childhood to the combined subtype in adulthood (38.6\%), followed by combined to hyperactive-impulsive (21.4\%), hyperactive-impulsive to combined (20.0\%), combined to inattentive (14.3\%), and hyperactive-impulsive to inattentive (5.7\%). There were no transitions from the inattentive to hyperactive-impulsive subtypes.

\section{Factors Associated With Childhood Subtype Stability}

Those whose ADHD subtype in childhood remained stable into adulthood did not differ from those who transitioned to a different subtype in terms of age, gender, family history of ADHD, CD symptoms, or past treatment with stimulant medication (Table 4). Subtype stability was significantly less likely among those with the inattentive childhood subtype and more likely among those with the combined childhood subtype, with these differences remaining significant after Holm-Bonferroni correction. 
Multivariable analysis of subtype stability between childhood and adulthood revealed that, after adjustment for potential confounding, having the combined subtype in childhood was the only significant independent predictor of overall subtype stability $\left(\mathrm{OR}_{\mathrm{adj}}=3.21,95 \% \mathrm{CI}\right.$ $=[1.25,8.26], p=.018)$.

The stability of specific childhood subtypes was also explored. Stability of the hyperactiveimpulsive subtype was associated with greater odds of a family history of ADHD $\left(\mathrm{OR}_{\mathrm{adj}}=\right.$ $7.10,95 \% \mathrm{CI}=[1.85,27.26])$ and stability of the combined subtype was more likely among those with symptoms of $\mathrm{CD}\left(\mathrm{OR}_{\mathrm{adj}}=4.70,95 \% \mathrm{CI}=[1.82,12.11], p=.003\right)$ and past stimulant treatment for $\mathrm{ADHD}\left(\mathrm{OR}_{\mathrm{adj}}=3.62,95 \% \mathrm{CI}=[1.87,7.02], p=.001\right)$. There were no significant independent predictors of stability of the inattentive subtype and further analysis of transitions from each childhood subtype to a different subtype in adulthood did not yield any significant findings.

\section{Discussion}

To our knowledge, this study provides the first cross-national data on the persistence of ADHD into adulthood among a treatment seeking SUD population. ADHD in childhood and adolescence was highly prevalent (22.7\%) and persistent: $72.8 \%$ of those meeting DSM-5 criteria for childhood ADHD also met criteria for adult ADHD. ADHD persistence was predicted by a family history of ADHD and childhood CD symptoms, and independently associated with comorbid ASPD.

The high prevalence of ADHD in the current sample is consistent with previous research (van Emmerik-van Oortmerssen et al., 2012), as are the low rates of previously established formal ADHD diagnosis and treatment (Bernardi et al., 2012; Faraone, Spencer, Montano, \& Biederman, 2004; Kaye, Darke, \& Torok, 2013; McAweeney, Rogers, Huddleston, Moore, $\&$ Gentile, 2010). Moreover, we found a full syndrome ADHD persistence rate in adulthood that is two- to fivefold that observed in outcome studies of childhood ADHD among nonSUD, clinically referred samples of ADHD patients. While two thirds of those with childhood ADHD may continue to have symptoms as adults to some extent, studies of ADHD persistence have typically found that only $15 \%$ to $35 \%$ of childhood cases of ADHD meet full diagnostic criteria for ADHD by adulthood (Biederman et al., 2011; Faraone et al., 2006).

In contrast to the decline in persistence associated with increasing age found among longitudinal studies of children with ADHD (Biederman, Mick, \& Faraone, 2000;

Biederman et al., 2010; Faraone et al., 2006), the current study found no association between age and the persistence of symptoms, even for hyperactive-symptoms, which are typically more likely to remit with increasing age. This finding may reflect the developmental course of ADHD, such that the decline in symptom persistence may be steeper up until early adulthood than beyond. As suggested by prospective and retrospective studies of adult ADHD that have also found no effect of age on persistence (Karam et al., 2015; Kessler et al., 2005), once ADHD has persisted into adulthood, age-related remission may be less likely. Importantly, the higher persistence rates than among other populations observed here 
may also reflect a greater severity and chronicity of ADHD among those seeking treatment for SUDs.

Consistent with previous research among non-SUD populations (Biederman et al., 1996; Biederman et al., 2000; Biederman et al., 2011; Biederman et al., 2010; Hart, Lahey, Loeber, Applegate, \& Frick, 1995), a family history of ADHD was the strongest predictor of the persistence of childhood ADHD into adulthood. The familiality and heritability of ADHD is well-documented. ADHD is a highly heritable disorder, with data from twin studies indicating that approximately $70 \%$ to $80 \%$ of the phenotypic variability is due to genetic influences (Faraone et al., 2005; Franke et al., 2012; Todd et al., 2001) and that heritability of clinically diagnosed ADHD remains high across the life span (Larsson, Chang,

D'Onofrio, \& Lichtenstein, 2014). Moreover, the developmental course of ADHD appears to have a strong genetic underpinning, with evidence for a primary role of genetic factors in ADHD symptom trajectories from childhood into adolescence (Pingault et al., 2015) and a higher familial risk for persistent ADHD than for ADHD that remits by adulthood (Franke et al., 2012).

As SUDs also have substantial heritability ( $\approx 0.5$; Urbanoski \& Kelly, 2012), it has been hypothesized that ADHD-SUD comorbidity reflects a shared genetic liability to both disorders (Biederman et al., 2008; Carpentier et al., 2013; Derks, Vink, Willemsen, van den Brink, \& Boomsma, 2014) and to externalizing pathology more broadly, including ASPD (Carragher et al., 2014). The association between familial ADHD and persistence of childhood ADHD in the current study suggests that this form of comorbidity in adulthood reflects a more severe phenotype of ADHD with a greater genetic loading. As all of the participants in the current study were seeking SUD treatment, the relative contribution of a genetic liability to persistent ADHD to the development and maintenance of SUD is unclear.

The presence of childhood CD symptoms also significantly predicted ADHD persistence. Moreover, ADHD continued to be associated with ASPD in adulthood, even after controlling for antisocial behavior associated with illicit drug use. These findings support those of earlier work in clinical SUD samples showing higher rates of ASPD among those with comorbid adult ADHD (Carpentier, van Gogh, Knapen, Buitelaar, \& De Jong, 2011).

ADHD is generally associated with an earlier onset and more severe course of SUDs. The present study, however, did not find any significant differences in SUD trajectories according to ADHD persistence or symptom presentation. This may reflect the nature of the current sample in that SUDs among a treatment seeking sample are likely to be at the more severe end of the spectrum (J. T. Young et al., 2015), regardless of whether ADHD has persisted or remitted. It is also possible that differences in SUD trajectories were obscured by the use of a categorical, rather than dimensional, approach to the measurement of ADHD. Previous research has found that when ADHD is measured on a continuum, increased symptom levels, even if below the diagnostic threshold, are associated with increased odds of SUD and that such approaches may be more sensitive in identifying clinically important variations in SUD risk (Ameringer \& Leventhal, 2013; Elkins et al., 2007). 
Although earlier onset and greater extent of illicit stimulant (i.e., cocaine, amphetamine) use among the persistent ADHD group was not significant after multiple comparison correction, the direction of the findings are consistent with some studies showing that, among treatment and community SUD samples, adult ADHD symptoms are associated with a preference for stimulants over other drug classes (Bihlar Muld, Jokinen, Bolte, \& Hirvikoski, 2013; Ginsberg, Hirvikoski, \& Lindefors, 2010), higher rates of stimulant dependence, and a greater frequency and chronicity of stimulant use (Kaye et al., 2013; Wilens et al., 2007; J. T. Young et al., 2015). As stimulants are considered effective first-line pharmacotherapy for ADHD, illicit stimulant use among those with ADHD is often speculated to be a form of "self-medication" of undiagnosed or untreated ADHD (Wilens et al., 2007; S. Young \& Sedgwick, 2015). Other studies, however, have not found a preference for stimulants among those with ADHD (van Emmerik-van Oortmerssen et al., 2012), possibly reflecting the high levels of polydrug use that are typical among illicit drug users (Darke \& Hall, 1995; van Emmerik-van Oortmerssen et al., 2012). Although a preference for stimulants associated with adult ADHD has not been unequivocally demonstrated, the persistence of ADHD may make longer term, higher frequency, and, consequently, problematic use of stimulants for their reinforcing and possibly "medicating" effects more likely.

Childhood maltreatment (e.g., physical/sexual abuse, neglect) has been associated with childhood and adult ADHD (Briscoe-Smith \& Hinshaw, 2006; Fuller-Thomson \& Lewis, 2015; Ouyang, Fang, Mercy, Perou, \& Grosse, 2008), while psychosocial childhood adversity more broadly has been shown to predict ADHD in childhood (Biederman et al., 1995; Kessler et al., 2005) and the persistence of ADHD into late adolescence (Biederman et al., 1996). In the current study, however, childhood adversity was not independently associated with ADHD persistence. Previous studies that have specifically examined the role of childhood adversity in predicting the persistence of ADHD into adulthood have likewise failed to demonstrate such an association (Kessler et al., 2005; Lara et al., 2009; McLaughlin et al., 2010). Childhood adversity is a well-documented antecedent to problematic substance use (Darke, 2013). Its potential moderating effect on ADHD persistence among those with SUDs, however, is not borne out by the current study, perhaps due to the high prevalence of childhood trauma in both the persistent and remitted ADHD groups, and has yet to be determined. Further studies may help to elucidate this relationship.

In accordance with previous research demonstrating an association between the combined subtype of ADHD and SUDs (Nogueira et al., 2014; Obermeit et al., 2013; Sprafkin et al., 2007; Tamm et al., 2012; Wilens et al., 2009), the combined subtype was the most common symptom presentation in both childhood and adult ADHD in this sample. Moreover, the combined subtype was the most stable presentation between childhood and adulthood, and this stability was significantly associated with a history of CD symptoms and past stimulant medication treatment of ADHD. ADHD symptoms causing sufficient impairment to require stimulant medication treatment and comorbid symptoms of $\mathrm{CD}$ indicate a greater severity of childhood ADHD. As such, a more severe adult symptom presentation with persistence of both inattentive and hyperactive-impulsive symptoms is not surprising and highlights the need to improve identification and management of adult ADHD among those with SUDs. 
These findings, along with the similarity in prevalence of the hyperactive-impulsive and inattentive subtypes throughout childhood and adulthood, suggest that SUDs may be associated with a different clinical manifestation and trajectory of ADHD than that typically seen in non-SUD populations. Among clinical and community samples, the inattentive subtype predominates (Wilens et al., 2009; Willcutt, 2012) and hyperactive-impulsive symptoms in childhood are more likely to remit by adulthood or become less impairing as people learn to channel their hyperactivity-impulsivity into careers and hobbies that will accommodate these tendencies. It would thus be reasonable to expect a transition from the combined subtype in childhood to the inattentive subtype in adulthood in a greater proportion of cases than we observed. Only one in seven transitioned from the combined to the inattentive subtype, whereas almost half of those with the inattentive and hyperactiveimpulsive subtypes in childhood transitioned to a combined subtype in adulthood. Although we were unable to identify any factors significantly associated with transitioning to the combined subtype, the developmental trajectories of ADHD symptoms in this group, and greater persistence of hyperactive-impulsive symptoms in particular, warrant further investigation to illuminate the likely mechanisms involved. It is possible that persistent impulsivity increases the likelihood of developing SUDs, but it is also plausible that chronic drug use, in and of itself, impairs prefrontal inhibitory function, via reduced dopamine transmission, resulting in greater impulsivity and hyperactivity (Volkow, Fowler, Wang, Baler, \& Telang, 2009).

There are a number of methodological limitations to be acknowledged. First, the representativeness of the sample of SUD treatment seekers in this study should be considered. Although the potential for selection bias cannot be discounted, there were no significant differences in the demographic and SUD profiles between those who participated in the study and those who dropped out prior to the full assessment phase (van de Glind et al., 2013). Therefore, potential bias due to study attrition is likely to be non-differential. Second, this was a predominantly male, Caucasian sample. As such, the findings may not be generalizable to populations with greater gender and ethnic diversity. It should be noted, however, that the gender distribution in our sample is consistent with that found in other SUD treatment seeking samples (European Monitoring Centre for Drugs and Drug Addiction, 2011). Third, the findings were based on retrospective self-report. With regard to the assessment of substance use history, carefully collected self-report data have been found to be a sufficiently reliable and valid measure for drug use patterns and associated problems (Darke, 1998; Ledgerwood, Goldberger, Risk, Lewis, \& Price, 2008). In cases where family networks were fractured, obtaining collateral information to support recall of childhood events was difficult. As such, information pertaining to familial and environmental risk factors may be subject to recall bias. Due to the likelihood that many participants would not have had access to informants willing or able to provide information confirming the presence of ADHD symptoms in childhood, collateral report was not a requirement for the diagnostic assessment of ADHD, nor was the lack of collateral information a criterion for exclusion from the study. Although the use of retrospective self-report may potentially lead to an underreporting of the presence and severity of symptoms of ADHD (Barkley, Fischer, Smallish, \& Fletcher, 2002), most adults have been found to accurately report their own symptoms of childhood and adult ADHD (Murphy \& Schachar, 2000). Moreover, studies 
have shown that, among those with a clinical diagnosis of adult ADHD, retrospective informant reports of childhood symptoms do not improve diagnostic accuracy over selfreport and may be even less reliable than the patient's own recall (Breda et al., 2015; Sandra Kooij et al., 2008). Finally, due to the cross-sectional study design, inferences regarding causal associations cannot be made. Although the predictors of persistence identified in the current study are consistent with the known risk factors for childhood ADHD (Banerjee, Middleton, \& Faraone, 2007; Froehlich et al., 2011; Warikoo \& Faraone, 2013) per se, it is possible that they are also associated with a greater severity of childhood ADHD which, in turn, is more likely to persist.

Although ADHD is prevalent and persistent among SUD treatment seekers and is associated with a more severe phenotype that is less likely to remit, it typically remains undiagnosed and untreated. Routine screening and follow-up assessment for ADHD and other externalizing disorders at treatment intake, to identify and manage this complex comorbidity, is critical to improving treatment outcomes. Moreover, given the neurobiological and clinical differences between persistent and remitted ADHD, there is a need for follow-up studies of those diagnosed in adulthood. In particular, studies investigating the clinical outcomes of treatment for comorbid adult ADHD and SUD and randomized controlled trials evaluating the sequence and effect of different treatment strategies are warranted.

\section{Acknowledgments}

The authors gratefully acknowledge the contribution to the IASP study of the following people: Atul Beniwal, Geert Bosma, Constanza Daigre, Therese Dahl, Romain Debrabant, Narelle Fordham, David Hay, Carlos Roncero, Kari Lossius, Eva Karin Løvaas, Marion Malivert, Merete Möller, Andrea Seitz, Laura Stevens, Rutger-Jan van der Gaag, Anneke van Wamel, and Sara Wallhed. We also thank the clients and staff of the participating treatment agencies for their assistance and wish to thank Dr. Natacha Carragher for providing statistical support.

\section{Funding}

The author(s) disclosed receipt of the following financial support for the research, authorship, and/or publication of this article: In the period of development of the IASP study (2005-2010), the ICASA network received unrestricted grants from the following pharmaceutical companies: Janssen-Cilag, Eli Lilly \& Company, and Shire. Since becoming a formal foundation (September 2010), the ICASA Foundation (www.adhdandsubstanceabuse.org) has operated independently from pharmaceutical funding, obtaining funding via the following sources: (a) participating institutes and (b) the Noaber Foundation, the Waterloo Foundation, and the Augeo Foundation. The funding companies, institutes, and foundations did not have, and will not have, influence on any aspect of the study, including research questions, data sampling, data management, data analyses, and publishing results. The ICASA Foundation arranged with institutes participating in the IASP study that each of these institutes would seek funding for their regional processes and data sampling efforts. The local institutes report the following funding sources: The Netherlands, Amsterdam: No external funding was obtained. The participating institute, Arkin, paid for the costs involved and used funding from Fonds Nuts Ohra for this project. Norway, Bergen Clinics Foundation: Main external funding has been the Regional research council for addiction in West Norway (Regionalt kompetansesenter for rusmiddelforskning i Helse Vest [KORFOR]), funding a 50\% position. The remaining resources, including staff and infrastructure, have been from the Bergen Clinics Foundation. Norway, Fredrikstad: The IASP was funded by the hospital, Sykehuset Østfold HF, not with money, but with 50\% of the salary of the participating professionals; the Regional Centre of Dual Diagnosis; and the Social and Health directory. Sweden, Stockholm: The study was funded by the Stockholm Centre for Dependency Disorders. Belgium: The IASP project in Belgium received private funding. France, Bordeaux: Financial support was received from a Research Grant PHRC (2006-2012) from the French Ministry of Health and a French National Research Agency PRA-CNRS-CHU-Bordeaux award (20082010). Spain, Barcelona: Financial support was received from Plan Nacional sobre Drogas, Ministerio de Sanidad y Política Social (PND 0080/2011); the Agència de Salut Pública de Barcelona; and the Departament de Salut, Government of Catalonia, Spain. Switzerland, Berne/Zurich: The IASP in Switzerland was funded by the Swiss Foundation of Alcohol Research (Grant No. 209). Hungary, Budapest: Financial support for this project was received from The European Union and the European Social Fund (Grant No. TÁMOP 4.2.1./B-09/1/ KMR2010-0003). Australia, Sydney/Perth: The IASP Screening Phase was funded by a Curtin University Strategic Research Faculty Grant. The National Drug and Alcohol Research Centre at UNSW Australia and the National 
Drug Research Institute at Curtin University are supported by funding from the Australian Government under the Substance Misuse Prevention and Service Improvements Grants Fund. L.D. is supported by an Australian NHMRC Principal Research Fellowship (No. 1041742). USA, Syracuse: No funding was obtained.

\section{Biographies}

Sharlene Kaye, $\mathrm{PhD}$, is a Senior Research Fellow at the National Drug and Alcohol Research Centre, University of New South Wales. Her research interests are in the areas of ADHD and substance use disorder comorbidity and psychostimulant-related harm. She is an active member of the International Collaboration on ADHD and Substance Abuse (ICASA).

Josep Antoni Ramos-Quiroga, MD, PhD, is an Associate Professor at the Department of Psychiatry and Legal Medicine at Universitat Autònoma de Barcelona, Spain, and head of the Department of Psychiatry at Hospital Universitari Vall d'Hebron. His research interests include the study of ADHD across the lifespan. He is Chair of the section Neurodevelopmental Disorders Across Lifespan of the European Psychiatric Association and is an active member of ICASA.

Geurt van de Glind, $\mathrm{PhD}$, is Senior Scientific Advisor of the Netherlands expert centre on Substance Use Disorders and addictive behaviors 'Stichting Resultaten Scoren'. He is the Director of ICASA. His research interests are substance use disorders in general and, more specifically, ADHD and substance use disorder comorbidity.

Frances R. Levin, MD, is the Kennedy-Leavy Professor of Psychiatry at Columbia University and Chief of the Division on Substance Abuse at NYSPI/Columbia University. Her research interests include pharmacologic and psychotherapeutic treatment interventions for cocaine and marijuana abuse, and treatment approaches for substance abusers with ADHD and other psychiatric illnesses. Dr. Levin is the Chair of the American Psychiatric Association's Council on Addictions and a member of the Interventions to Prevent and Treat Addictions Study Section for the National Institute of Health.

Stephen V. Faraone, PhD, is a Distinguished Professor in the Departments of Psychiatry and Neuroscience \& Physiology at SUNY Upstate Medical University. He is also Senior Scientific Advisor to the Research Program in Pediatric Psychopharmacology at the Massachusetts General Hospital and a lecturer at Harvard Medical School. Dr. Faraone studies the nature and causes of mental disorders in childhood and has made contributions to research in psychiatric genetics, psychopharmacology, diagnostic issues and methodology.

Steve Allsop, PhD, is Professor and Director of the National Drug Research Institute, Curtin University, Australia. His research interests include drug policy and prevention of alcohol and drug related problems and enhancing treatment engagement and effectiveness. He is Deputy Chair of the Australian National Advisory Council on Alcohol and Drugs.

Louisa Degenhardt, PhD, is Professor of Epidemiology and NHMRC Principal Research Fellow at the National Drug and Alcohol Research Centre, University of New South Wales. She leads a program of epidemiological research, including the examination of mortality related to opioid antagonist treatment; post marketing surveillance of new opioid agonist 
pharmacotherapies; studies of drug overdose and international studies of the epidemiology of drug use and dependence. Louisa also works in collaboration with the World Health Organization (WHO) and UNAIDS examining the epidemiology of illicit drug use and associated health risks across the globe.

Franz Moggi, PhD, is an Associate Professor of Clinical Psychology and head psychologist at the University Hospital of Psychiatry, University of Bern, Switzerland. His research interests are in the areas of addiction treatment and treatment of comorbidities of psychiatric and substance use disorders. He is also a member of ICASA.

Csaba Barta, MD, PhD, is an Assistant Professor at the Institute of Medical Chemistry, Molecular Biology and Pathobiochemisry at Semmelweis University, Budapest, Hungary. As a molecular geneticist specializing in psychiatric genetics his main research interest is substance dependence, ADHD and Tourette's syndrome. He participates in a number of large international collaborations, e.g. TS-Eurotrain: Interdisciplinary training network for Tourette Syndrome (FP7-PEOPLE-2012-Marie Curie ITN), as well as ICASA.

Maija Konstenius, $\mathrm{PhD}$, is a post-doctoral researcher at the Department of Clinical Neuroscience, Karolinska Institutet, and Stockholm Health Care Services, Centre for Psychiatry Research, Stockholm, Sweden. Her research interests are in the areas of treatment of ADHD and drug dependence. She is an active member of ICASA.

Johan Franck, MD, PhD, is a full professor of Psychiatry and Addiction at the Karolinska Institutet, Stockholm, Sweden. His research interests are in the areas of the neurobiology and treatment of substance use disorders, with emphasis on medication development. He is a member of ICASA.

Arvid Skutle, PsyD, is head of research at the Bergen Clinics Foundation, Norway, and a member of ICASA. His research interest has been in substance use disorders, comorbid conditions like ADHD, and novel compounds on the international internet market. His research focus has been on prevalence studies, validation of instruments, and treatment evaluations.

Eli-Torild Bu, PhD, is a researcher and clinical psychologist at The Bergen Clinics Foundation. Her current research interests are the treatment of pathological gambling and gaming as well as ADHD and substance use disorder comorbidity.

Maarten W. J. Koeter, PhD, was Associate Professor of Research Methods and Statistics at the Department of Psychiatry of the Academic Medical Center of the University of Amsterdam. His main interest was in state-of-the-art designs and statistical analyses of studies in the field of addiction and psychiatry. Sadly, Dr. Koeter passed away in January 2016.

Zsolt Demetrovics, $\mathrm{PhD}$, DSc, is a clinical psychologist and cultural anthropologist. He is Professor of Psychology at the Eötvös Loránd University, Budapest, Hungary, where he serves as Director of the Institute of Psychology and head of the Department of Clinical 
Psychology \& Addiction. He has published numerous research papers on the epidemiology and psychological background of substance use behavior and behavioral addictions including gambling, online gaming, internet addiction, exercise addiction and compulsive buying. He is Editor-in-Chief of the Journal of Behavioral Addictions.

Máté Kapitány-Fövény, $\mathrm{PhD}$, is a psychologist at Nyírő Gyula Hospital - National Institute of Psychiatry and Addictions, and a lecturer at Semmelweis University, Budapest, Hungary. His primary research interests include the study of novel psychoactive substances, comoridity of addictive behaviors, utility of virtual tools in both addiction research and prevention of substance use. He is also a member of ICASA.

Robert A. Schoevers, MD, PhD, is Professor of Psychiatry, head of the Department of Psychiatry at the University Medical Center Groningen, and director of the Research School of Behavioural and Cognitive Neurosciences, University of Groningen, The Netherlands.

Katelijne van Emmerik-van Oortmerssen, MD, is a psychiatrist at the Arkin Mental Health Care and Addiction Treatment Center, Amsterdam, The Netherlands. Her current research interests include the treatment of ADHD and substance use disorder comorbidity using integrated cognitive behavioral therapy.

Pieter-Jan Carpentier, MD, $\mathrm{PhD}$, is the head psychiatrist of the adult ADHD treatment programm of the psychiatric institute Reinier van Arkel in 's-Hertogenbosch, The Netherlands. He has a long-standing interest in ADHD and addiction.

Geert Dom, MD, PhD, is a Professor of Addiction Psychiatry at the Antwerp University (UA), and the medical director of the Psychiatric Center Alexian Brothers, Boechout, Belgium. His research interests are addictive behaviors and psychiatric co-morbidity.

Sofie Verspreet is a clinical psychologist at the Psychiatric Center Alexian Brothers, Boechout, Belgium.

Cleo L. Crunelle, PhD, is a post-doctoral researcher at the University Hospital Brussels (UZ Brussel) in Brussels, Belgium, and at the Toxicological Center of the Antwerp University in Antwerp, Belgium. Her research interests are in the areas of the neurobiology and treatment of drug dependence. She is an active member of ICASA.

Jesse T. Young, MPH, is a Research Fellow at the Melbourne School of Population and Global Health, The University of Melbourne, and holds Adjunct research positions at the School of Population Health, The University of Western Australia and the National Drug Research Institute, Curtin University. Specializing in psychiatric epidemiology, his research interests include comorbid mental health and substance use disorders, intellectual disability and justice health. He is a member of ICASA and the Society for Mental Health Research.

Susan Carruthers, $\mathrm{PhD}$, is an Adjunct Fellow at the National Drug Research Institute, Curtin University. Susan's research interests are in the area of injecting drug use and the prevention of blood borne virus infection. 
Joanne Cassar, MPsych (Clin), has worked as a Senior Research Officer and Psychologist at the National Drug and Alcohol Research Centre, University of New South Wales. She currently works as the Clinical Psychologist at the University of New South Wales Fatigue Clinic, whilst also working in a private practice part time.

Melina Fatséas, MD, PhD, HDR, is a Senior Lecturer and researcher at the University of Bordeaux (Addiction Research Team of Sanpsy CNRS USR 3413) and medical director of the Addiction Parenthood Treatment and Support Unit at the Ch. Perrens Hospital, Bordeaux, France.

Marc Auriacombe, MD, is a full professor of Psychiatry and Addiction at the University of Bordeaux (France) and team leader of the Addiction Research Team of Sanpsy CNRS USR 3413. He is also the medical director of the Addiction Treatment Center of $\mathrm{CH}$ Ch. Perrens and CHU de Bordeaux, Bordeaux, France.

Brian Johnson, MD, is the Director of Addiction Psychiatry and Professor of Psychiatry and Behavioral Sciences at SUNY Upstate Medical University. He has published extensively in scientific and medical journals about addiction, psychiatry, neuropsychoanalysis, and the effects of various drugs.

Matthew Dunn, PhD, is a Senior Lecturer in Public Health at Deakin University and a Conjoint Senior Lecturer at the National Drug and alcohol Research Centre, University of New South Wales. His research interests include monitoring trends in substance use and harm, the use of performance and image enhancing drugs, and ADHD and substance use disorder comorbidity.

Ortal Slobodin is a clinical psychologist and a researcher at the Neuro-Cognitive Center of Hadassah-Hebrew University Medical Center. Her primary research interests are assessment and treatment of ADHD.

Wim van den Brink, $\mathrm{MD}, \mathrm{PhD}$, is a full professor of Psychiatry and Addiction at the Academic Medical Center of the University of Amsterdam in Amsterdam, The Netherlands. His research interests are in the areas of the neurobiology and treatment of addiction. He is the president of the International Collaboration on ADHD and Substance Abuse (ICASA).

\section{References}

American Psychiatric Association. Diagnostic and statistical manual of mental disorders. 4th. Washington, DC: Author; 1994.

American Psychiatric Association. Diagnostic and statistical manual of mental disorders. 4th. Washington, DC: Author; 2000. text rev

American Psychiatric Association. Diagnostic and statistical manual of mental disorders. 5th. Arlington, VA: American Psychiatric Publishing; 2013.

Ameringer KJ, Leventhal AM. 2013; Associations between attention deficit hyperactivity disorder symptom domains and DSM-IV lifetime substance dependence. American Journal on Addictions. 22:23-32. [PubMed: 23398223] 
Arias AJ, Gelernter J, Chan G, Weiss RD, Brady KT, Farrer L, Kranzler HR. 2008; Correlates of cooccurring ADHD in drug-dependent subjects: Prevalence and features of substance dependence and psychiatric disorders. Addictive Behaviors. 33:1199-1207. [PubMed: 18558465]

Banerjee TD, Middleton F, Faraone SV. 2007; Environmental risk factors for attention-deficit hyperactivity disorder. Acta Paediatrica. 96:1269-1274. [PubMed: 17718779]

Barkley RA, Fischer M, Smallish L, Fletcher K. 2002; The persistence of attention-deficit/ hyperactivity disorder into young adulthood as a function of reporting source and definition of disorder. Journal of Abnormal Psychology. 111:279-289. [PubMed: 12003449]

Bernardi S, Faraone SV, Cortese S, Kerridge BT, Pallanti S, Wang S, Blanco C. 2012; The lifetime impact of attention deficit hyperactivity disorder: Results from the National Epidemiologic Survey on Alcohol and Related Conditions (NESARC). Psychological Medicine. 42:875-887. [PubMed: 21846424]

Biederman J, Faraone S, Milberger S, Curtis S, Chen L, Marrs A, Spencer T. 1996; Predictors of persistence and remission of ADHD into adolescence: Results from a four-year prospective followup study. Journal of the American Academy of Child \& Adolescent Psychiatry. 35:343-351. [PubMed: 8714323]

Biederman J, Mick E, Faraone SV. 2000; Age-dependent decline of symptoms of attention deficit hyperactivity disorder: Impact of remission definition and symptom type. American Journal of Psychiatry. 157:816-818. [PubMed: 10784477]

Biederman J, Milberger S, Faraone SV, Kiely K, Guite J, Mick E, Reed E. 1995; Family-environment risk factors for attention-deficit hyperactivity disorder. A test of Rutter's indicators of adversity. Archives of General Psychiatry. 52:464-470. [PubMed: 7771916]

Biederman J, Petty CR, Clarke A, Lomedico A, Faraone SV. 2011; Predictors of persistent ADHD: An 11-year follow-up study. Journal of Psychiatric Research. 45:150-155. [PubMed: 20656298]

Biederman J, Petty CR, Evans M, Small J, Faraone SV. 2010; How persistent is ADHD? A controlled 10-year follow-up study of boys with ADHD. Psychiatry Research. 177:299-304. [PubMed: 20452063]

Biederman J, Petty CR, O’Connor KB, Hyder LL, Faraone SV. 2012; Predictors of persistence in girls with attention deficit hyperactivity disorder: Results from an 11-year controlled follow-up study. Acta Psychiatrica Scandinavica. 125:147-156. [PubMed: 22097933]

Biederman J, Petty CR, Wilens TE, Fraire MG, Purcell CA, Mick E, Faraone SV. 2008; Familial risk analyses of attention deficit hyperactivity disorder and substance use disorders. American Journal of Psychiatry. 165:107-115. [PubMed: 18006872]

Bihlar Muld B, Jokinen J, Bolte S, Hirvikoski T. 2013; Attention deficit/hyperactivity disorders with co-existing substance use disorder is characterized by early antisocial behaviour and poor cognitive skills. BMC Psychiatry. 13

Breda V, Rovaris DL, Vitola ES, Mota NR, Blaya-Rocha P, Salgado CAI, Grevet EH. 2015; Does collateral retrospective information about childhood attention-deficit/hyperactivity disorder symptoms assist in the diagnosis of attention-deficit/hyperactivity disorder in adults? Findings from a large clinical sample. Australian and New Zealand Journal of Psychiatry. doi: $10.1177 / 0004867415609421$

Briscoe-Smith AM, Hinshaw SP. 2006; Linkages between child abuse and attention-deficit/ hyperactivity disorder in girls: Behavioral and social correlates. Child Abuse \& Neglect. 30:12391255. [PubMed: 17097140]

Carpentier PJ, Arias Vasquez A, Hoogman M, Onnink M, Kan CC, Kooij JJS, Buitelaar JK. 2013; Shared and unique genetic contributions to attention deficit/hyperactivity disorder and substance use disorders: A pilot study of six candidate genes. European Neuropsychopharmacology. 23:448457. [PubMed: 22841130]

Carpentier PJ, van Gogh MT, Knapen LJ, Buitelaar JK, De Jong CA. 2011; Influence of attention deficit hyperactivity disorder and conduct disorder on opioid dependence severity and psychiatric comorbidity in chronic methadone-maintained patients. European Addiction Research. 17:10-20. [PubMed: 20881401]

Carragher N, Krueger RF, Eaton NR, Markon KE, Keyes KM, Blanco C, Hasin DS. 2014; ADHD and the externalizing spectrum: Direct comparison of categorical, continuous, and hybrid models of 
liability in a nationally representative sample. Social Psychiatry and Psychiatric Epidemiology. 49:1307-1317. [PubMed: 24081325]

Chang Z, Lichtenstein P, Larsson H. 2012; The effects of childhood ADHD symptoms on early-onset substance use: A Swedish twin study. Journal of Abnormal Child Psychology. 40:425-435. [PubMed: 21947618]

Charach A, Yeung E, Climans T, Lillie E. 2011; Childhood attention-deficit/hyperactivity disorder and future substance use disorders: Comparative meta-analyses. Journal of the American Academy of Child and Adolescent Psychiatry. 50:9-21. [PubMed: 21156266]

Conroy E, Degenhardt L, Mattick RP, Nelson EC. 2009; Child maltreatment as a risk factor for opioid dependence: Comparison of family characteristics and type and severity of child maltreatment with a matched control group. Child Abuse \& Neglect. 33:343-352. [PubMed: 19477004]

Darke S. 1998; Self-report among injecting drug users: A review. Drug and Alcohol Dependence. 51:253-263. [PubMed: 9787998]

Darke S. 2013; Pathways to heroin dependence: Time to reappraise self-medication. Addiction. 108:659-667. [PubMed: 23075121]

Darke S, Hall W. 1995; Levels and correlates of polydrug use among heroin users and regular amphetamine users. Drug and Alcohol Dependence. 39:231-235. [PubMed: 8556972]

Darke S, Kaye S, Finlay-Jones R. 1998; Antisocial personality disorder, psychopathy and injecting heroin use. Drug and Alcohol Dependence. 52:63-69. [PubMed: 9788008]

Derks EM, Vink JM, Willemsen G, van den Brink W, Boomsma DI. 2014; Genetic and environmental influences on the relationship between adult ADHD symptoms and self-reported problem drinking in 6024 Dutch twins. Psychological Medicine. 44:2673-2683. [PubMed: 24957628]

Elkins IJ, McGue M, Iacono WG. 2007; Prospective effects of attention-deficit/hyperactivity disorder, conduct disorder, and sex on adolescent substance use and abuse. Archives of General Psychiatry. 64:1145-1152. [PubMed: 17909126]

Epstein, JE, Johnson, DE, Conners, CK. Conners' Adult ADHD Diagnostic Interview for DSM-IV (CAADID): Technical manual. Toronto, ON, Canada: Multi-Health Systems Inc. (MHS); 2001.

European Monitoring Centre for Drugs and Drug Addiction. Annual report 2011: The state of the drugs problem in Europe. Luxembourg: Publications Office of the European Union; 2011.

Faraone SV, Biederman J, Mick E. 2006; The age-dependent decline of attention deficit hyperactivity disorder: A meta-analysis of follow-up studies. Psychological Medicine. 36:159-165. [PubMed: 16420712]

Faraone SV, Perlis RH, Doyle AE, Smoller JW, Goralnick JJ, Holmgren MA, Sklar P. 2005; Molecular genetics of attention-deficit/hyperactivity disorder. Biological Psychiatry. 57:1313-1323. [PubMed: 15950004]

Faraone SV, Spencer TJ, Montano CB, Biederman J. 2004; Attention-deficit/hyperactivity disorder in adults: A survey of current practice in psychiatry and primary care. Archives of Internal Medicine. 164:1221-1226. [PubMed: 15197048]

Faraone SV, Wilens TE, Petty C, Antshel K, Spencer T, Biederman J. 2007; Substance use among ADHD adults: Implications of late onset and subthreshold diagnoses. American Journal on Addictions. 16:24-32.

Farrugia PL, Mills KL, Barrett E, Back SE, Teesson M, Baker A, Brady KT. 2011; Childhood trauma among individuals with co-morbid substance use and post traumatic stress disorder. Mental Health and Substance Use. 4:314-326. [PubMed: 21984884]

Franke B, Faraone SV, Asherson P, Buitelaar J, Bau CHD, Ramos-Quiroga JA, Reif A. 2012; The genetics of attention deficit/hyperactivity disorder in adults, a review. Molecular Psychiatry. 17:960-987. [PubMed: 22105624]

Froehlich TE, Anixt JS, Loe IM, Chirdkiatgumchai V, Kuan L, Gilman RC. 2011; Update on environmental risk factors for attention-deficit/hyperactivity disorder. Current Psychiatry Reports. 13:333-344. [PubMed: 21779823]

Fuller-Thomson E, Lewis DA. 2015; The relationship between early adversities and attention-deficit/ hyperactivity disorder. Child Abuse \& Neglect. 47:94-101. [PubMed: 25890666]

Ginsberg Y, Hirvikoski T, Lindefors N. 2010; Attention deficit hyperactivity disorder (ADHD) among longer-term prison inmates is a prevalent, persistent and disabling disorder. BMC Psychiatry. 10 
Hart EL, Lahey B, Loeber R, Applegate B, Frick PJ. 1995; Developmental change in attention-deficit hyperactivity disorder in boys: A four-year longitudinal study. Journal of Abnormal Child Psychology. 23:729-749. [PubMed: 8609310]

IBM Corp. IBM SPSS Statistics for Windows (Version 22). Armonk, NY: Author; 2013.

Karam RG, Breda V, Picon FA, Rovaris DL, Victor MM, Salgado CA, Bau CH. 2015; Persistence and remission of ADHD during adulthood: A 7-year clinical follow-up study. Psychological Medicine. 45:2045-2056. [PubMed: 25612927]

Kaye S, Darke S, Finlay-Jones R. 1998; The onset of heroin use and criminal behaviour: Does order make a difference? Drug and Alcohol Dependence. 53:79-86. [PubMed: 10933342]

Kaye S, Darke S, Torok M. 2013; Attention deficit hyperactivity disorder (ADHD) among illicit psychostimulant users: A hidden disorder? Addiction. 108:923-931. [PubMed: 23227816]

Kessler RC, Adler LA, Barkley R, Biederman J, Conners CK, Faraone SV, Zaslavsky AM. 2005; Patterns and predictors of attention-deficit/hyperactivity disorder persistence into adulthood: Results from the national comorbidity survey replication. Biological Psychiatry. 57:1442-1451. [PubMed: 15950019]

Lara C, Fayyad J, de Graaf R, Kessler RC, Aguilar-Gaxiola S, Angermeyer M, Sampson N. 2009; Childhood predictors of adult attention-deficit/hyperactivity disorder: Results from the World Health Organization World Mental Health Survey Initiative. Biological Psychiatry. 65:46-54. [PubMed: 19006789]

Larsson H, Chang Z, D'Onofrio BM, Lichtenstein P. 2014; The heritability of clinically diagnosed attention deficit hyperactivity disorder across the lifespan. Psychological Medicine. 44:2223-2229. [PubMed: 24107258]

Ledgerwood DM, Goldberger BA, Risk NK, Lewis CE, Price RK. 2008; Comparison between selfreport and hair analysis of illicit drug use in a community sample of middle-aged men. Addictive Behaviors. 33:1131-1139. [PubMed: 18547737]

Lee SS, Humphreys KL, Flory K, Liu R, Glass K. 2011; Prospective association of childhood attention-deficit/hyperactivity disorder (ADHD) and substance use and abuse/dependence: A metaanalytic review. Clinical Psychology Review. 31:328-341. [PubMed: 21382538]

Mattfeld AT, Gabrieli JD, Biederman J, Spencer T, Brown A, Kotte A, Whitfield-Gabrieli S. 2014; Brain differences between persistent and remitted attention deficit hyperactivity disorder. Brain. 137(Pt 9):2423-2428. [PubMed: 24916335]

McLaughlin KA, Green JG, Gruber MJ, Sampson NA, Zaslavsky AM, Kessler RC. 2010; Childhood adversities and adult psychiatric disorders in the national comorbidity survey replication II: Associations with persistence of DSM-IV disorders. Archives of General Psychiatry. 67:124-132. [PubMed: 20124112]

Molina BS, Pelham WE Jr. 2003; Childhood predictors of adolescent substance use in a longitudinal study of children with ADHD. Journal of Abnormal Psychology. 112:497-507. [PubMed: 12943028]

Murphy P, Schachar R. 2000; Use of self-ratings in the assessment of symptoms of attention deficit hyperactivity disorder in adults. American Journal of Psychiatry. 157:1156-1159. [PubMed: 10873926]

Nogueira M, Bosch R, Valero S, Gomez-Barros N, Palomar G, Richarte V, Ramos-Quiroga JA. 2014; Early-age clinical and developmental features associated to substance use disorders in attentiondeficit/hyperactivity disorder in adults. Comprehensive Psychiatry. 55:639-649. [PubMed: 24411652]

Obermeit LC, Cattie JE, Bolden KA, Marquine MJ, Morgan EE, Franklin DR Jr, Woods SP. 2013; Attention-deficit/hyperactivity disorder among chronic methamphetamine users: Frequency, persistence, and adverse effects on everyday functioning. Addictive Behaviors. 38:2874-2878. [PubMed: 24018233]

Ouyang L, Fang X, Mercy J, Perou R, Grosse SD. 2008; Attention-deficit/hyperactivity disorder symptoms and child maltreatment: A population-based study. The Journal of Pediatrics. 153:851856. [PubMed: 18619612] 
Pingault JB, Viding E, Galera C, Greven CU, Zheng Y, Plomin R, Rijsdijk F. 2015; Genetic and environmental influences on the developmental course of attention-deficit/hyperactivity disorder symptoms from childhood to adolescence. JAMA Psychiatry. 72:651-658. [PubMed: 25945901]

Sandra Kooij JJ, Marije Boonstra A, Swinkels SHN, Bekker EM, de Noord I, Buitelaar JK. 2008; Reliability, validity, and utility of instruments for self-report and informant report concerning symptoms of ADHD in adult patients. Journal of Attention Disorders. 11:445-458. [PubMed: 18083961]

Shaw P, Sudre G, Wharton A, Weingart D, Sharp W, Sarlls J. 2015; White matter microstructure and the variable adult outcome of childhood attention deficit hyperactivity disorder. Neuropsychopharmacology. 40:746-754. [PubMed: 25241803]

Sheehan DV, Lecrubier Y, Sheehan KH, Amorim P, Janavs J, Weiller E, Dunbar GC. 1998; The MiniInternational Neuropsychiatric Interview (M.I.N.I.): The development and validation of a structured diagnostic psychiatric interview for DSM-IV and ICD-10. Journal of Clinical Psychiatry. 59(Suppl 20):22-33.

Sprafkin J, Gadow KD, Weiss MD, Schneider J, Nolan EE. 2007; Psychiatric comorbidity in ADHD symptom subtypes in clinic and community adults. Journal of Attention Disorders. 11:114-124. [PubMed: 17494828]

Sullivan MA, Rudnik-Levin F. 2001; Attention deficit/hyperactivity disorder and substance abuse. Diagnostic and therapeutic considerations. Annals of the New York Academy of Sciences. 931:251-270. [PubMed: 11462745]

Tamm L, Adinoff B, Nakonezny PA, Winhusen T, Riggs P. 2012; Attention-deficit/hyperactivity disorder subtypes in adolescents with comorbid substance-use disorder. The American Journal of Drug and Alcohol Abuse. 38:93-100. [PubMed: 21834613]

Todd RD, Rasmussen ER, Neuman RJ, Reich W, Hudziak JJ, Bucholz KK, Heath A. 2001; Familiarity and heritability of subtypes of attention deficit hyperactivity disorder in a population sample of adolescent female twins. American Journal of Psychiatry. 158:1891-1898. [PubMed: 11691697]

Turgay A, Goodman DW, Asherson P, Lasser RA, Babcock TF, Pucci ML, Barkley R. 2012; Lifespan persistence of ADHD: The life transition model and its application. Journal of Clinical Psychiatry. 73:192-201. [PubMed: 22313720]

Urbanoski KA, Kelly JF. 2012; Understanding genetic risk for substance use and addiction: A guide for non-geneticists. Clinical Psychology Review. 32:60-70. [PubMed: 22155620]

van de Glind G, Konstenius M, Koeter MWJ, van Emmerik-van Oortmerssen K, Carpentier PJ, Kaye S, van den Brink W. 2014; Variability in the prevalence of adult ADHD in treatment seeking substance use disorder patients: Results from an international multi-center study exploring DSMIV and DSM-5 criteria. Drug and Alcohol Dependence. 134:158-166. [PubMed: 24156882]

van de Glind G, van Emmerik-van Oortmerssen K, Carpentier PJ, Levin FR, Koeter MWJ, Barta C, van den Brink W. 2013; The International ADHD in Substance Use Disorders Prevalence (IASP) study: Background, methods and study population. International Journal of Methods in Psychiatric Research. 22:232-244. [PubMed: 24022983]

van Emmerik-van Oortmerssen K, van de Glind G, Koeter MW, Allsop S, Auriacombe M, Barta C, Schoevers RA. 2014; Psychiatric comorbidity in treatment-seeking substance use disorder patients with and without attention deficit hyperactivity disorder: Results of the IASP study. Addiction. 109:262-272. [PubMed: 24118292]

van Emmerik-van Oortmerssen K, van de Glind G, van den Brink W, Smit F, Crunelle CL, Swets M, Schoevers RA. 2012; Prevalence of attention-deficit hyperactivity disorder in substance use disorder patients: A meta-analysis and meta-regression analysis. Drug and Alcohol Dependence. 122:11-19. [PubMed: 22209385]

Volkow ND, Fowler JS, Wang GJ, Baler R, Telang F. 2009; Imaging dopamine's role in drug abuse and addiction. Neuropharmacology. 56(Suppl 1):3-8. [PubMed: 18617195]

Warikoo N, Faraone SV. 2013; Background, clinical features and treatment of attention deficit hyperactivity disorder in children. Expert Opinion on Pharmacotherapy. 14:1885-1906. [PubMed: 23865438]

Wilens TE, Adamson J, Sgambati S, Whitley J, Santry A, Monuteaux MC, Biederman J. 2007; Do individuals with ADHD self-medicate with cigarettes and substances of abuse? Results from a 
controlled family study of ADHD. The American Journal on Addictions. 16:14-23. [PubMed: 17453603]

Wilens TE, Biederman J, Faraone SV, Martelon M, Westerberg D, Spencer TJ. 2009; Presenting ADHD symptoms, subtypes, and comorbid disorders in clinically referred adults with ADHD. Journal of Clinical Psychiatry. 70:1557-1562. [PubMed: 20031097]

Wilens TE, Martelon M, Joshi G, Bateman C, Fried R, Petty C, Biederman J. 2011; Does ADHD predict substance-use disorders? A 10-year follow-up study of young adults with ADHD. Journal of the American Academy of Child and Adolescent Psychiatry. 50:543-553. [PubMed: 21621138]

Willcutt EG. 2012; The prevalence of DSM-IV attention-deficit/hyperactivity disorder: A metaanalytic review. Neurotherapeutics. 9:490-499. [PubMed: 22976615]

Williams JB, Gibbon M, First MB, Spitzer RL, Davies M, Borus J, Wittchen HU. 1992; The Structured Clinical Interview for DSM-III-R (SCID): II. Multisite test-retest reliability. Archives of General Psychiatry. 49:630-636. [PubMed: 1637253]

Young JT, Carruthers S, Kaye S, Allsop S, Gilsenan J, Degenhardt L, Preen D. 2015; Comorbid attention deficit hyperactivity disorder and substance use disorder complexity and chronicity in treatment-seeking adults. Drug and Alcohol Review. 34:683-693. DOI: 10.1111/dar.12249 [PubMed: 25790353]

Young S, Sedgwick O. 2015; Attention deficit hyperactivity disorder and substance misuse: An evaluation of causal hypotheses and treatment considerations. Expert Review of Neurotherapeutics. 15:1005-1014. [PubMed: 26289485] 


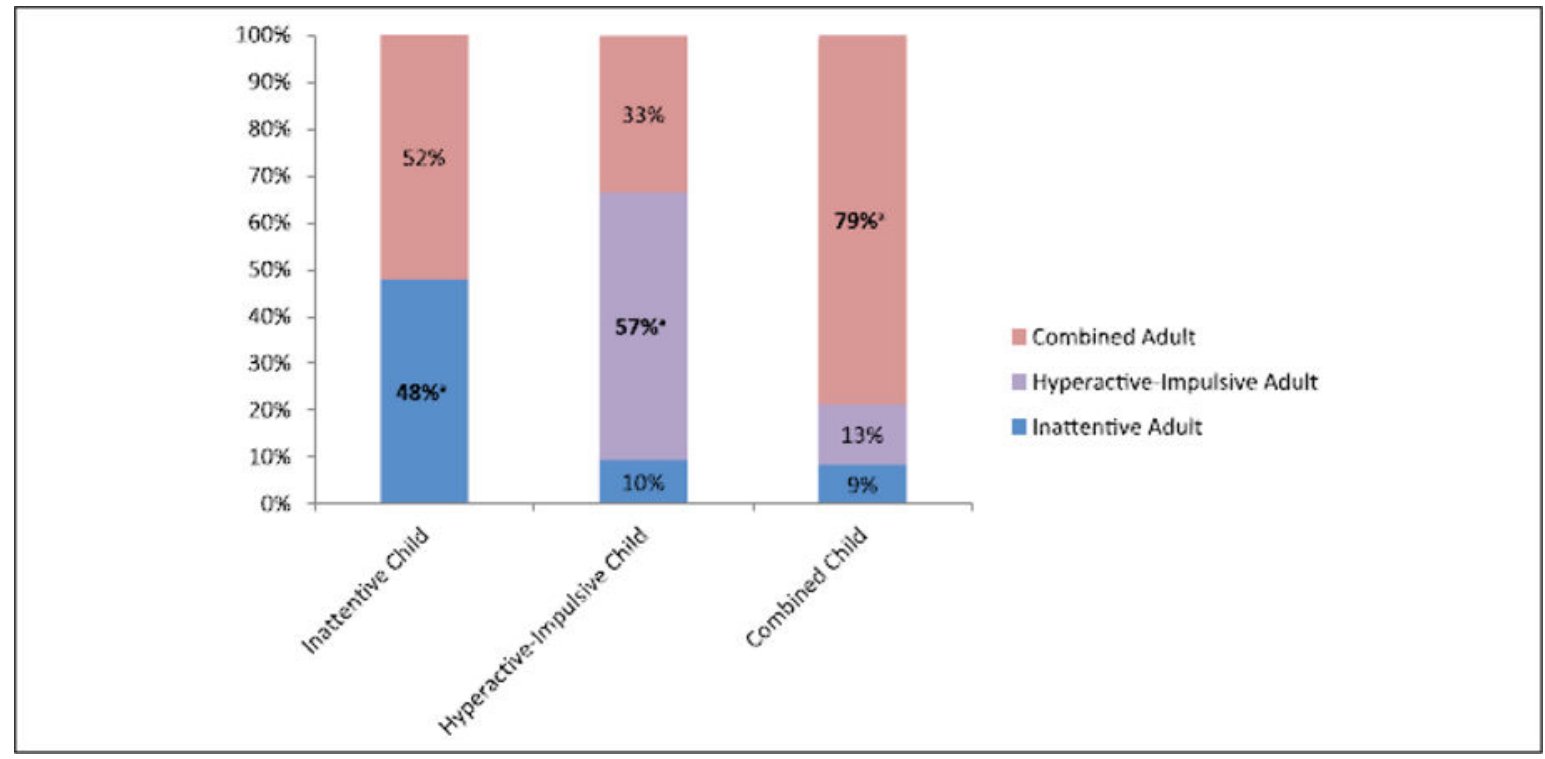

Figure 1.

Stability of childhood ADHD subtypes among those with persistent ADHD.

andicates subtype stability (i.e., child subtype = adult subtype). 
Table 1

Sample Characteristics According to Persistence or Remission of Childhood ADHD Into Adulthood.

\begin{tabular}{|c|c|c|c|c|}
\hline & $\begin{array}{l}\text { Persistent ADHD } \\
\quad(n=211)\end{array}$ & $\begin{array}{l}\text { Remitted ADHD } \\
\quad(n=79)\end{array}$ & $\begin{array}{c}\text { Unadjusted OR }(95 \% \text { CI }) \text { or } t \text { - } \\
\text { statistic }\end{array}$ & $\begin{array}{l}\text { Uncorrected } \\
p \text { values }\end{array}$ \\
\hline Mean age $(S D)$ & $35.6(9.6)$ & $36.1(10.4)$ & $t_{287}=-0.38$ & $p=.704$ \\
\hline Range & $18-63$ & $18-60$ & & \\
\hline$\%$ Male & 76.8 & 79.7 & OR $1.19[0.63,2.25]$ & $p=.590$ \\
\hline$\%$ Caucasian & 95.8 & 93.0 & OR $1.74[0.55,5.52]$ & $p=.345$ \\
\hline$\%$ Graduated high school $^{a}$ & 47.6 & 40.3 & OR $1.35[0.76,2.39]$ & $p=.310$ \\
\hline$\%$ Unemployed $^{b}$ & 72.8 & 74.4 & OR $0.92[0.51,1.67]$ & $p=.788$ \\
\hline$\%$ Married/de facto relationship ${ }^{c}$ & 10.3 & 17.2 & OR $0.55[0.25,1.24]$ & $p=.151$ \\
\hline$\%$ Inpatient SUD treatment setting $d$ & 31.6 & 41.8 & OR $0.64[0.38,1.10]$ & $p=.105$ \\
\hline $\begin{array}{l}\% \text { Diagnosed with ADHD prior to study } \\
\text { entry } d\end{array}$ & 21.1 & 24.1 & OR $0.84[0.46,1.56]$ & $p=.583$ \\
\hline $\begin{array}{l}\% \text { Past stimulant medication treatment } \\
\text { for } \mathrm{ADHD}^{e}\end{array}$ & 16.1 & 10.3 & OR $1.68[0.74,3.81]$ & $p=.216$ \\
\hline $\begin{array}{l}\% \text { Current stimulant medication } \\
\text { treatment for } \mathrm{ADHD}^{f}\end{array}$ & 8.6 & 5.7 & OR $1.56[0.32,7.46]$ & $p=.580$ \\
\hline
\end{tabular}

Note. $\mathrm{OR}=$ odds ratios $; \mathrm{CI}=$ confidence intervals; $\mathrm{SUD}=$ substance use disorder.

$a_{n=235 .}$

$b_{n=280}$

$c_{n=248 .}$

$d_{n=288}$

$e_{n=283}$.

$f_{n=151 .}$ 
Table 2

Drug Use Correlates of ADHD Persistence.

\begin{tabular}{|c|c|c|c|c|}
\hline & $\begin{array}{l}\text { Persistent ADHD } \\
\quad(n=211)\end{array}$ & $\underset{(n=79)}{\text { Remitted ADHD }}$ & Unadjusted OR (95\% CI) or $t$-statistic & $\begin{array}{c}\text { Uncorrected } \\
p \text { values }\end{array}$ \\
\hline \multicolumn{5}{|c|}{ Primary substance of concern $(\%)^{a}$} \\
\hline Alcohol & 35.1 & 51.9 & OR $0.50[0.29,0.85]$ & $p=.010^{\dagger}$ \\
\hline Illicit drugs & 64.9 & 48.1 & OR $2.00[1.18,3.40]$ & $p=.010^{\dagger}$ \\
\hline Heroin & 12.0 & 9.1 & OR $1.37[0.57,3.30]$ & $p=.488$ \\
\hline Amphetamine & 17.8 & 6.5 & OR $3.12[1.18,8.25]$ & $p=.022^{\dagger}$ \\
\hline Cocaine & 12.0 & 2.6 & OR $5.12[1.18,22.17]$ & $p=.029^{\dagger}$ \\
\hline Cannabis & 15.4 & 22.1 & OR $0.64[0.33,1.24]$ & $p=.186$ \\
\hline Benzodiazepines & 3.8 & 5.2 & OR $0.73[0.21,2.50]$ & $p=.616$ \\
\hline \multicolumn{5}{|l|}{ Age of first use (mean) } \\
\hline Nicotine & 14.3 & 14.4 & $t_{143}=-0.17$ & $p=.867$ \\
\hline Alcohol (<5 glasses) & 14.7 & 15.2 & $t_{182}=-0.56$ & $p=.579$ \\
\hline Alcohol (>5 glasses) & 16.7 & 18.7 & $t_{83}=-1.72$ & $p=.089$ \\
\hline Heroin & 22.3 & 20.1 & $t_{69}=1.45$ & $p=.150$ \\
\hline Methadone & 28.4 & 32.4 & $t_{39}=-0.91$ & $p=.368$ \\
\hline Cocaine & 21.5 & 21.0 & $t_{132}=0.45$ & $p=.653$ \\
\hline Amphetamines & 18.9 & 21.2 & $t_{135}=-2.11$ & $p=.037^{\dagger \dagger}$ \\
\hline Cannabis & 15.9 & 16.4 & $t_{189}=-0.75$ & $p=.454$ \\
\hline Benzodiazepines & 22.8 & 24.3 & $t_{114}=-0.84$ & $p=.403$ \\
\hline \multicolumn{5}{|l|}{ Regular use (mean years) } \\
\hline Nicotine & 20.3 & 19.1 & $t_{137}=0.63$ & $p=.531$ \\
\hline Alcohol (>5 glasses) & 13.4 & 14.0 & $t_{196}=-0.37$ & $p=.711$ \\
\hline Heroin & 7.7 & 7.4 & $t_{61}=0.12$ & $p=.906$ \\
\hline Methadone & 3.8 & 3.7 & $t_{37}=0.08$ & $p=.936$ \\
\hline Cocaine & 5.8 & 3.3 & $t_{69}=2.56$ & $p=.013^{\dagger \dagger}$ \\
\hline Amphetamines & 8.7 & 6.3 & $t_{123}=1.21$ & $p=.227$ \\
\hline Cannabis & 12.0 & 12.2 & $t_{172}=-0.10$ & $p=.917$ \\
\hline Benzodiazepines & 7.2 & 5.5 & $t_{104}=1.13$ & $p=.260$ \\
\hline \multicolumn{5}{|c|}{ Days used past month (mean) } \\
\hline Nicotine & 28.1 & 26.3 & $t_{53}=1.04$ & $p=.302$ \\
\hline Alcohol (>5 glasses) & 10.3 & 13.5 & $t_{202}=-1.63$ & $p=.105$ \\
\hline Heroin & 3.2 & 1.1 & $t_{62}=0.94$ & $p=.351$ \\
\hline Methadone & 11.7 & 16.0 & $t_{39}=-0.68$ & $p=.502$ \\
\hline Cocaine & 3.6 & 1.1 & $t_{70}=2.10$ & $p=.040^{\dagger \dagger}$ \\
\hline Amphetamines & 3.9 & 3.3 & $t_{118}=0.28$ & $p=.784$ \\
\hline Cannabis & 9.5 & 11.9 & $t_{172}=-1.09$ & $p=.277$ \\
\hline
\end{tabular}

J Atten Disord. Author manuscript; available in PMC 2019 October 01. 


\begin{tabular}{|c|c|c|c|c|}
\hline & $\begin{array}{c}\text { Persistent ADHD } \\
\quad(n=211)\end{array}$ & $\underset{(n=79)}{\text { Remitted ADHD }}$ & Unadjusted OR (95\% CI) or $t$-statistic & $\begin{array}{l}\text { Uncorrected } \\
p \text { values }\end{array}$ \\
\hline Benzodiazepines & 11.8 & 14.8 & $t_{106}=-1.04$ & $p=.301$ \\
\hline \multicolumn{5}{|c|}{ Polydrug use (mean no. drug classes) } \\
\hline Lifetime & 4.0 & 3.4 & $t_{259}=2.05$ & $p=.041^{\dagger \dagger}$ \\
\hline Recent & 1.8 & 1.6 & $t_{259}=0.96$ & $p=.336$ \\
\hline
\end{tabular}

Note. $\mathrm{OR}=$ odds ratios $\mathrm{CI}=$ confidence intervals.

${ }_{n=285}$.

${ }^{\dagger} p$ value not significant after correcting for multiple comparisons (corrected $p<.007$ ).

${ }^{\dagger} p$ value not significant after correcting for multiple comparisons (corrected $p<.006$ ).

$t^{t} p$ value not significant after correcting for multiple comparisons (corrected $p<.025$ ) 


\section{Table 3}

Early Predictors of ADHD Persistence.

\begin{tabular}{|c|c|c|c|c|}
\hline & $\begin{array}{c}\text { Persistent ADHD }(n= \\
\text { 211 })\end{array}$ & $\begin{array}{c}\text { Remitted ADHD } \\
\text { 79) }\end{array}$ & Unadjusted OR (95\% CI) & Uncorrected $p$ values \\
\hline \multicolumn{5}{|l|}{$\%$ ADHD childhood subtype } \\
\hline Inattentive & 24.6 & 25.3 & OR $0.96[0.53,1.75]$ & $p=.906$ \\
\hline Hyperactive-impulsive & 19.9 & 32.9 & OR $0.51[0.28,0.90]$ & $p=.021^{\dagger}$ \\
\hline Combined & 55.5 & 41.8 & OR $1.74[1.03,2.93]$ & $p=.039^{\dagger}$ \\
\hline$\%$ Family history of ADHD ${ }^{a}$ & 38.7 & 21.5 & OR $2.30[1.17,4.55]$ & $p=.016^{*}$ \\
\hline \multicolumn{5}{|l|}{$\%$ In utero exposure $b$} \\
\hline Nicotine & 37.8 & 40.8 & OR $0.88[0.50,1.55]$ & $p=.657$ \\
\hline Alcohol & 15.6 & 18.6 & OR $0.81[0.39,1.68]$ & $p=.573$ \\
\hline Illicit drugs & 1.2 & 2.9 & OR $0.40[0.05,2.88]$ & $p=.361$ \\
\hline \multicolumn{5}{|l|}{$\%$ Childhood adversity ${ }^{c}$} \\
\hline \multicolumn{5}{|l|}{ Trauma } \\
\hline Sexual abuse & 23.4 & 18.3 & OR $1.37[0.68,2.74]$ & $p=.381$ \\
\hline Physical abuse & 40.6 & 47.9 & OR $0.74[0.43,1.29]$ & $p=.294$ \\
\hline Emotional abuse & 55.4 & 49.3 & OR $1.28[0.74,2.22]$ & $p=.383$ \\
\hline Other trauma & 76.3 & 60.0 & OR $2.15[1.19,3.88]$ & $p=.012^{\dagger \dagger}$ \\
\hline Any trauma & 84.0 & 81.7 & OR $1.18[0.57,2.43]$ & $p=.660$ \\
\hline Family violence & 40.6 & 40.8 & OR $0.99[0.56,1.73]$ & $p=.968$ \\
\hline Neglect & 41.4 & 25.4 & OR $2.08[1.12,3.84]$ & $p=.020^{\dagger \dagger}$ \\
\hline$\%$ Conduct disorder symptoms ${ }^{d}$ & 69.0 & 51.4 & OR $2.10[1.21,3.67]$ & $p=.009^{*}$ \\
\hline
\end{tabular}

Note. $\mathrm{OR}=$ odds ratios $\mathrm{CI}=$ confidence intervals.

${ }_{n}=172$.

$b_{n=243 \text {. }}$

$c_{n=246 .}$

$d_{n=259}$

${ }^{\dagger} p$ value not significant after correcting for multiple comparisons (corrected $p<.017$ ).

${ }^{\dagger} p$ value not significant after correcting for multiple comparisons (corrected $p<.008$ ).

$$
\text { * }
$$

* $p$ value significant at $p<.05$.

$J$ Atten Disord. Author manuscript; available in PMC 2019 October 01. 


\section{Table 4}

Factors Associated With Childhood Subtype Stability.

\begin{tabular}{lcccc}
\hline & $\begin{array}{c}\text { Stable childhood } \\
\text { subtype }(\boldsymbol{n}=\mathbf{1 4 1})\end{array}$ & $\begin{array}{c}\text { Unstable childhood } \\
\text { subtype }(\boldsymbol{n}=\mathbf{7 0})\end{array}$ & Unadjusted OR (95\% CI) & $\begin{array}{c}\text { Uncorrected } \\
\boldsymbol{p} \text { values }\end{array}$ \\
\hline Mean age & 35.5 & 35.8 & $t_{208}=-0.18$ & $p=.860$ \\
\% Male & 78.0 & 74.3 & OR $0.81[0.42,1.59]$ & $p=.546$ \\
\% Family history of ADHD & 37.3 & 42.3 & OR $0.81[0.32,2.04]$ & $p=.657$ \\
\% Conduct disorder symptoms & 73.3 & 61.2 & OR $1.74[0.92,3.30]$ & $p=.087$ \\
\% Past stimulant medication treatment for & 16.8 & 14.7 & OR $1.17[0.52,2.62]$ & $p=.703$ \\
ADHD & & & & \\
\% Childhood subtype & 17.7 & 38.6 & OR $0.34[0.18,0.66]$ & $p=.001 *$ \\
$\quad$ Inattentive & 17.0 & 25.7 & OR $0.59[0.30,1.18]$ & $p=.139$ \\
$\quad$ Hyperactive-impulsive & 65.2 & 35.7 & OR 3.38 [1.86, 6.15] & $p<.001 *$ \\
$\quad$ Combined & & &
\end{tabular}

Note. $\mathrm{OR}=$ odds ratios $\mathrm{CI}=$ confidence intervals.

$p$ value significant after correcting for multiple comparisons (corrected $p<.017$ ). 